\title{
A comparative study on decision and documentation of refraining from resuscitation in two medical home care units in Sweden
}

\author{
Bogdan Sterpu', Pia Lindman ${ }^{2}$ and Linda Björkhem-Bergman ${ }^{2,3,4^{*}}$
}

\begin{abstract}
Background: A decision to refrain from cardiopulmonary resuscitation (CPR) in the case of cardiac arrest is recommended in terminally ill patients to avoid unnecessary suffering at time of death. The aim of this study was to describe the frequency of decisions and documentation of "do not attempt cardiopulmonary resuscitation" (DNACPR) in two Medical Home Care Units in Stockholm. Unit A had written guidelines about how to document CPR-decisions in the medical records, including a requirement for a decision to be taken (CPR: yes/no) while Unit B had no such requirement.

Method: The medical records for all patients in palliative phase of their disease at the two Units were reviewed. Data was collected on documentation of decisions about CPR (yes/no), DNACPR-decisions and documentation regarding whether the patient or next-of-kin had been informed about the DNACPR-decision.

Results: In the two Units, 316 and 219 patients in palliative phase were identified. In Unit A 100\% of the patients had a CPR-decision (yes/no) compared to $79 \%$ in Unit B $(p<0.001)$. There was no statistically significant difference in DNACPR-decisions between the two Units, 43 and 37\%. Documentation about informing the patient regarding the decision was significantly higher in Unit A, 53\% compared to $14 \%$ at Unit B $(p<0.001)$. Documentation about informing the next-of-kin was also significantly higher at Unit A; 42\% compared to $6 \%$ at Unit B $(p<0.001)$.

Conclusion: Less than $50 \%$ of patients in palliative phase had a decision of DNACPR in two Medical Home Care Units in Stockholm. The presence of written guidelines and a requirement for a CPR-decision did not increase the frequency of DNACPR-decisions but was associated with a higher frequency of documentation of decisions and of information given to both the patients and the next-of-kin.
\end{abstract}

Keywords: Palliative care, Decision, Cardiopulmonary resuscitation, Documentation

\section{Introduction}

In Sweden, Medical Home Care Units offer hospital-like care at home to both oncological and non-oncological patients. Most of the enrolled patients suffer from a chronic, life-threatening disease, i.e. patients in palliative phase of a disease. A minority of the patients have other

\footnotetext{
* Correspondence: linda.bjorkhem-bergman@ki.se

${ }^{2}$ ASIH Stockholm Södra, Medical Home Care and Hospice Ward, Bergtallsvägen 12, SE-125 59 Älvsjö, Sweden

${ }^{3}$ Karolinska Institutet, Department of Neurobiology, Care Sciences and Society (NVS), Division of Clinical Geriatrics, Blickagången 16, Neo floor 7, SE-141 83 Huddinge, Sweden

Full list of author information is available at the end of the article
}

non-palliative conditions but need supportive medical care at home for some time. The overall aim of the Medical Home Care is to provide good palliative and/or supporting care to the patients in their own homes and to avoid hospital admissions. The Medical Home Care also facilitates the possibility to be cared for at home during the final days of life and allows patients to die at home. In this context the decision to refrain from cardiopulmonary resuscitation $(\mathrm{CPR})$ in the case of cardiac arrest needs to be addressed and discussed with the patient and the next-of-kin $[1,2]$.

(c) The Author(s). 2019 Open Access This article is distributed under the terms of the Creative Commons Attribution 4.0 International License (http://creativecommons.org/licenses/by/4.0/), which permits unrestricted use, distribution, and reproduction in any medium, provided you give appropriate credit to the original author(s) and the source, provide a link to the Creative Commons license, and indicate if changes were made. The Creative Commons Public Domain Dedication waiver (http://creativecommons.org/publicdomain/zero/1.0/) applies to the data made available in this article, unless otherwise stated. 
When CPR was first described in the 1960s as a lifesaving action in people who experienced sudden cardiac arrest it was never intended to be used in terminally ill patients $[3,4]$. However, it soon became a routine practice to perform CPR in all cases of cardiac arrest - also in patients with chronic illness, and even in dying patients [4]. Yet, the decision to refrain from CPR is often difficult to take for the physician and is an emotionally charged discussion to have with the patients and the next-of-kin [5]. Most importantly, CPR might result in unnecessary suffering for the dying patient [4].

The outcome of CPR is generally poor in most people and the survival rate varies between 10 and $20 \%$ according to studies from different countries around the world [2, 6-8]. However, the outcome of CPR is even worse in patients with cancer or other severe illnesses. In a systematic review including 31 studies it was shown that cancer patients had a survival rate of $6 \%$ following CPR, and the survival rate was as low as $2 \%$ in patients with advanced cancer [4]. In a review comprising 18 studies on the success rate of inhospital CPR in patients with advanced cancer, being in palliative phase of the disease, i.e. the same kind of patients enrolled in Medical Home Care in Sweden, the success rate was close to zero [9]. However, it is rather common that a decision to "do not attempt cardiopulmonary resuscitation" (DNACPR) has not been taken been taken in this group of patients.

According to the Swedish law, it is advisable but not absolutely necessary that a DNACPR-decision is taken in agreement with the patient (http://www.riksdagen.se/ sv/dokument-lagar/dokument/svensk-forfattningssamling/patientlag-2014821_sfs-2014-821). In addition, it is recommended that the patient and the next-of-kin are informed about the decision of refraining from CPR in the case of cardiac arrest (http://www.riksdagen.se/sv/ dokument-lagar/dokument/svensk-forfattningssamling/ patientlag-2014821_sfs-2014-821). According to a survey made in Sweden in June 2018 it was shown that there were significant shortages in the information regarding the DNACPR-decision given to patients and the next-ofkin (http://sverigesradio.se/sida/artikel.aspx?programid= $83 \&$ artikel $=6972774$ ). This led to a national debate in the Swedish media about DNACPR-decisions.

In the Stockholm Region there are two Medical Home Care Units that are financed by the County Council; ASIH Stockholm Södra, hereafter referred to as "Unit A", and ASIH Stockholm Norr, hereafter referred to as "Unit B". The two Units are described in more detail in the methods section. At Unit A, written guidelines about decision taking and documentation regarding the DNACPR-decision were introduced in 2017. These guidelines included a requirement to take a decision about CPR (CPR: yes or no), which had to be stated in the medical records. Unit B had no such obligatory requirement about CPR-decisions.

The aim of this study was to describe the frequency of decision and documentation related to DNACPR in these two Medical Home Care Units in Stockholm and to investigate if the requirement for a CPR-decision influenced the frequency of DNACPR-decisions.

\section{Methods \\ Description of the two medical home care units from this study}

The two Medical Home Care Units in this study enrol the same kind of patients and have the same commission from the Swedish National Health Authorities. Unit A has approximately 380 enrolled patients and Unit B has approximately 280 enrolled patients on any given day. The median care time at the Units is approximately 3-4 months. In addition to the Medical Home Care facilities, both Units have an in-patient Hospice Ward for mainly end-of-life patients with short lifetime expectancy. The Hospice Ward at Unit A has 16 beds and Unit B has 12 beds. The median care time at the Hospice Wards are 10-14 days.

There are 20 senior consultants working at Unit A and 18 working at Unit B. The senior consultants have different backgrounds, but all have 5 years of specialist training in one of the disciplines: oncology, family medicine, internal medicine, geriatrics, clinical pharmacology, nephrology, hematology or anesthesia. Palliative Medicine is an additional specialty in Sweden (2 years training after the 5 years of specialist training), and approximately $50 \%$ of the senior consultants in both Units had specialist training in Palliative Medicine.

At Unit A it was mandatory to state in the medical record what should be done in the case of cardiac arrest (CPR: yes/no) according to new written guidelines introduced in 2017. Unit B had chosen not to have such a requirement for CPR-decision documentation. Both Units had the same electronic system for medical records and the same documentation templates. At both Units the decision about DNACPR (if present) was stated in a specific subheading in a template called "Individual Care Plan" that is present for all patients enrolled at both Units.

Both Units had joint education about the poor outcome of CPR in patients being in palliative phase of their disease. In addition, staff from Unit A had additional meetings discussing the new guidelines regarding the requirement to take a specific decision about CPR, how to document the decision in the medical records, and information that the decision should be regularly evaluated.

\section{Review of medical records}

A retrospective study was performed to compare the frequency of decision taking and documentation of DNACPR 
in the two Medical Home Care Units. All medical records were reviewed at each Unit on a given day.

At Unit A, one physician (PL) reviewed all "Individual Care Plans" at a specific date in January 2019. At Unit B, one physician (BS) reviewed all "Individual Care Plans" for all patients at the Unit on a randomly selected day in November 2018. The review comprised both outpatients enrolled to the Advanced Medical Home Care and in-patients at the Hospice Wards.

The review of medical records was performed approximately 1.5 years after the introduction of written guidelines on decision making and documentation at Unit A.

For each patient the following data was collected: palliative phase of disease (yes/no), documentation of what to do in case of cardiac arrest and the decision of DNACPR (yes/no), documentation if the patients were informed about the decision (yes/no or unknown) and whether the next-of-kin was informed about the decision (yes/no or unknown).

\section{Definition of patients in palliative phase}

Only patients being in palliative phase of their disease were included in the final analysis, i.e. patients suffering from a life-limiting disease with a short life-time expectancy and in need of palliative care. This includes patients suffering from an advanced cancer, but also patients with other life-threatening diseases with a short lifetime expectancy, i.e. patients with late-stage heart failure, late-stage chronic obstructive pulmonary disease (COPD) and late-stage kidney failure. In case of uncertainty as to whether the patients were in palliative phase or not, the medical records were reviewed by two different physicians (LBB and PL for patients in Unit A, and by LBB and BS for patients in Unit B) and a joint decision about whether a patient could be defined as being a palliative phase or not was taken.

\section{Statistical analysis}

Statistical analysis was performed using Graph-Pad Prism version 6.0. The comparison between the two Units (yes or no decision) was performed by Fishers exact test. A significance of $p \leq 0.05$ was considered as statistically significant. The comparison between the two Units regarding patient age was performed using student's t-test.

\section{Ethical statement}

The review of the medical records was approved by the Regional Ethical Committee in Stockholm, Dnr 2018/ 1798-31. Both studies were also approved by the Unit Director at each Unit. All data extracted from the medical records was anonymised before analysis to ensure that no individual patient could be identified in the dataset or the analysis.

\section{Results}

At Unit A, 372 patients were enrolled, of which 316 were in palliative phase. At Unit B, 272 patients were enrolled on the specific day, and 219 were in palliative phase of their disease (Fig. 1). Most of the patients in the Units were cancer patients. The demographic data of the study population is presented in Table 1 .

Among all patients defined as being in palliative phase of their disease, $100 \%$ had a decision about CPR (yes/no) at Unit A and $79 \%$ at Unit B, as shown in Fig. 1. The difference between the two Units was statistically significant $(p<0.001)$ (Fig. 2).

At Unit A, $43 \%$ of the patients had a decision about DNACPR in the case of cardiac arrest and at Unit B there were $37 \%$ of patients who had taken this decision. This difference was not statistically significant $(p=0.88)$, (Fig. 2). An "attempt CPR-decision" was present in 57\% of all patients in palliative phase at Unit A compared to $50 \%$ at Unit $\mathrm{B},(p=0.11)$ (Table 1$)$.

At the in-patient Hospice Wards all patients had a DNACPR-decision in both Units, $n=16$ and $n=12$ respectively (Table 1).

In the cases where the decision about DNACPR had been taken, it was documented in the medical record that the patients had been informed in $54 \%$ of the cases at Unit A, but was only documented in the medical records of $14 \%$ of the patients at Unit B. Documentation about information to next-to-kin was present in $42 \%$ of cases at Unit A and 6\% of cases at Unit B (Fig. 2).

\section{Discussion}

This study showed that the decision of DNACPR in patients in palliative phase of their disease enrolled to two Medical Home Care Units in Stockholm is documented in less than $50 \%$ of cases. Written guidelines about DNACPR-documentation and the requirement for a CPR-decision did not increase the frequency of DNACPR decision taking.

It could be hypothesized that the presence of written guidelines would encourage the physicians to take more DNACPR-decisions, but this was not observed in this study. Instead, the physicians were more accurate to document what to do in the case of cardiac arrest, and all patients had a decision, i.e. "attempt CPR" or "do not attempt CPR" at Unit A. A total of $57 \%$ of all patients at Unit A being in palliative phase of the disease had an "attempt CPR-decision" compared to $50 \%$ at Unit B. In Unit B, $21 \%$ of the patients lacked documentation of formal decision about what to do in case of cardiac arrest and thus the physician would be required to take an onthe-spot decision in the case of cardiac arrest.

Moreover, the staff at Unit A had had meetings discussing the new guidelines and this did not results in a 


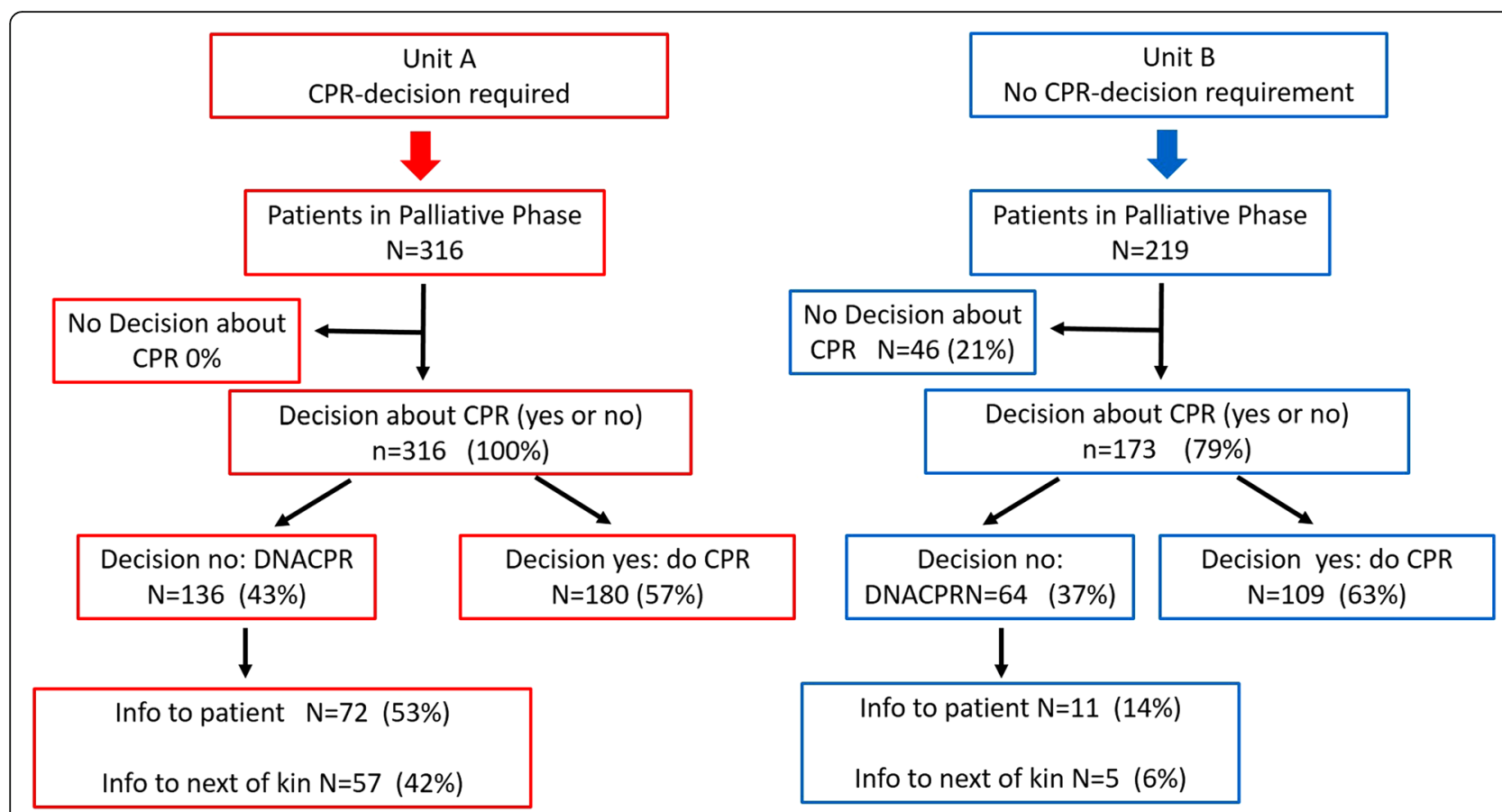

Fig. 1 Flow chart of patients included in the study from the two Medical Home Care Units in Stockholm, Sweden, including the frequency of the presence of a decision and documentation about cardiopulmonary resuscitation (CPR) in the case of cardiac arrest

higher frequency of DNACPR-decision but improved the documentation.

As described in the introduction, the outcome when performing CPR to patients with life-limiting diagnosis is very poor and often unsuccessful $[4,9]$. The success rate of CPR in the general Swedish population in the case of cardiac arrest has been reported to be approximately $10 \%[2,6]$. The success rate of CPR in patients with life-limiting illnesses has never been studied in a
Swedish population but is likely very low, comparable with reports from other countries i.e. $0-2 \%[4,9]$. However, the decision not to perform CPR is difficult to take even if the physicians are well-informed about the poor outcome of CPR.

Studies on the decision of CPR (yes or no) is vastly different between countries. In a study performed on 151 in-hospital patients in New Zealand, 27\% had a decision about CPR (yes/no) in the medical records [10]. In a

Table 1 Demographic data of the patients in palliative phase, enrolled at two Medical Home Care Units in Stockholm, that were included in this study

\begin{tabular}{|c|c|c|c|}
\hline & $\begin{array}{l}\text { Unit A } \\
\text { (CPR-decision mandatory) }\end{array}$ & $\begin{array}{l}\text { Unit B } \\
\text { (CPR-decision not mandatory) }\end{array}$ & $p$-value \\
\hline Patients in palliative phase & $N=316$ & $N=219$ & NA \\
\hline Average age (range) & 69 years (23-95) & 73 years (18-99) & $p=0.88$ \\
\hline Men & $49 \% N=155$ & $49 \% N=108$ & $p=1.00$ \\
\hline Women & $51 \% N=161$ & $51 \% N=111$ & $p=1.00$ \\
\hline Decision about CPR (yes or no) & $100 \% N=316$ & $79 \% N=173$ & $p<0.001$ \\
\hline Decision of "attempt CPR" & $57 \% N=180$ & $50 \% N=109$ & $p=0.11$ \\
\hline Decision of "do not attempt CPR" (DNACPR) & $43 \% N=136$ & $37 \% N=81$ & $p=0.21$ \\
\hline $\begin{array}{l}\text { Decision of DNACPR } \\
\text { In-patients / Hospice Ward }\end{array}$ & $100 \% N=16$ & $100 \% N=12$ & $p=1.00$ \\
\hline $\begin{array}{l}\text { DNACPR decision: } \\
\text { Information to patient }\end{array}$ & $53 \% N=72$ & $14 \% N=11$ & $p<0.001$ \\
\hline $\begin{array}{l}\text { DNACPR decision: } \\
\text { Information to next-of-kin }\end{array}$ & $42 \% N=57$ & $6 \% N=5$ & $p<0.001$ \\
\hline
\end{tabular}




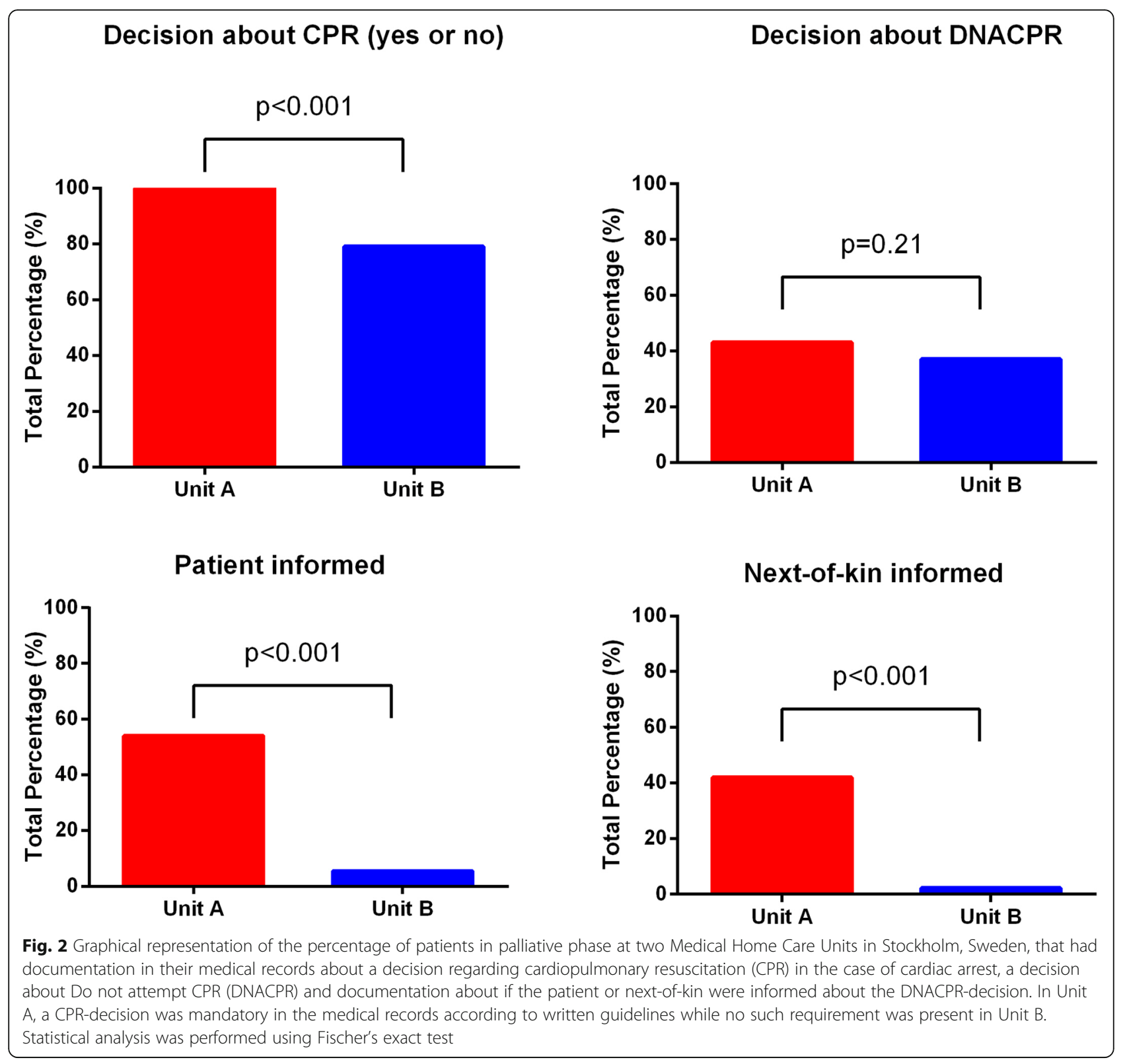

Canadian study on 205 patients referred to palliative radiotherapy, a DNACPR-decision had only been taken in $4 \%$ of cases, and an "attempt CPR-decision" had been taken in $3 \%$ of cases, while in $93 \%$ of cases no decision was taken [11].

Our results are in contrast to a study performed in the UK showing a statistically significant increase in CPR decisions after the introduction of a Form of Treatment Options for patients where the CPR-decisions increased from 52 to $77 \%$ [12].

According to several studies, patients with terminal illnesses want to be involved in the decision of DNACPR and the care planning $[13,14]$. Moreover, it has been shown that there is often a miss-match between the patient's preferences for CPR and the physician's perceptions about the wish of the patient [15]. The results from these studies emphasize the importance of physicianpatient discussion about CPR. In the home care setting there is also a need for involving the next-of-kin in the discussion of CPR since they are often present at the time of death [1]. The present study does not answer the question about the involvement of the patient or of the next-of-kin in the decision taking but the results suggest that most patients and next-of-kin were not informed about the decision.

It should be noted that it is more common that nononcological patients with terminal illnesses are exposed to $\mathrm{CPR}$ at time of death compared to oncological 
patients [16-19]. Thus, it is particularly important to identify non-oncological patients who are in the end-oflife stage, and to ensure that the physician has the courage to discuss the DNACPR-decision with them in order to avoid the suffering connected to the CPR-measures at time of death [20-22].

In Wales, UK, a new approach to tackle the sensitive issue of DNACPR discussions was developed in 2015 called "TalkCPR" [23]. This educational program included websites, videos and media pads aimed at both patients and healthcare professionals [23]. This approach was very successful, and physicians exposed to the education reported that they discussed DNACPR more frequently with their patients and felt more comfortable with the discussion.

Many patients have a poor knowledge of CPR and the majority overestimate the success rate of CPR [14, 24]. Notably, physicians also often overestimate the success rate of CPR [24]. In a study where in-patients were randomized to watch a video about CPR or about "standard care", the patients that watched the video were less likely to want CPR in the case of cardiac arrest in comparison with the group exposed to "standard care" [25]. The study indicated that appropriate patient education might facilitate the decisions and the discussion about DNACPR.

\section{Limitations}

This study has several limitations. First, the study is a retrospective, observational study on the frequency of documentation of DNACPR and no adjustments for possible cofounding factors were made. However, the two Units enroll patients with similar conditions and have the same commission from the Stockholm County Council. The physicians at both Units had been exposed to the same education about CPR. The only difference between the Units was the presence of written guidelines at the Unit A including the requirement for a CPR-decision to be taken. Finally, it should be stressed that although it was not documented in the medical records, both patients and next-of-kin may have been informed about the DNACPR-decision. Since there were no guidelines that urged the physician to write the decision in the medical records in Unit B this might influence the result of what was found in the medical records and may not necessary mean that no information had been provided. In Stockholm the patient has access to their own medical records online since 2018. Thus, the patients have the possibility to find the information about the CPR-decisions by themselves and as such the physicians may not think it was necessary to note in the medical records that the patient was informed.

\section{Recommendations and future perspectives}

A study performed in Taiwan showed that the phrasing in the medical record "to allow natural death" versus "do not resuscitate" was perceived as positive and easier to accept when a decision about not attempting CPR was to be taken [26]. Perhaps this phrasing would make it easier for the physician to write the DNACPR-decision in the medical record and this could be a good option in Sweden where the patient has online access to their medical records.

The results presented here show that education of the physicians about poor outcome of CPR and written guidelines about decision making was not enough for more DNACPR-decisions to be taken. Previous studies show the importance of education of the patients about the outcome of CPR [13, 14, 23]. Thus, in future studies a prospective design should be employed with an intervention including different educational approaches for patients about CPR. In addition, a study exploring factors and views that influence the physician's decision about DNACPR in Medical Home Care is warranted.

\section{Conclusion}

This study showed that less than $50 \%$ of patients considered as being in palliative phase of their disease had a decision of DNACPR in two Medical Home Care Units in Stockholm. Written guidelines and the requirement for a CPR-decision did not increase the overall frequency of DNACPR decisions but were associated with a higher frequency of documentation in the medical records about decisions taken and information given to patients and the next-of-kin.

\section{Abbreviations}

CPR: Cardiopulmonary resuscitation; DNACPR: Do not attempt CPR

\section{Acknowledgments \\ The authors would like to express their sincere gratitude to the Unit Directors of the two Medical Home Care Units, Anna Ström (RN) and Carin Joelsson (MD), for supporting and facilitating the study and to Laura Plant (MSc, PhD) for critical reading and language revision of the manuscript.}

\section{Authors' contributions}

BS conceived with the idea of the study. BS, PL and LBB designed the study. $B S$ and $P L$ performed the review of the medical records. BS, PL and LBB analyzed and interpreted the data. LBB wrote the first draft of the manuscript and BS, PL and LBB contributed, read and accepted the final version of the manuscript. All authors read and approved the final manuscript.

\section{Authors' information}

BS and PL are working as senior consultants in the Advanced Medical Home Care in Stockholm, BS at ASIH Stockholm Norr and PL at ASIH Stockholm Södra. LBB is senior consultant at the Hospice Ward at ASIH Stockholm

Södra. LBB is also Associate Professor in Clinical Pharmacology and research group leader in Palliative Medicine at Karolinska Institute, Stockholm, Sweden.

\section{Funding}

This study was financially supported by grants from Stockholm County Council (ALF 20160036 and 20180320), the Swedish Cancer Society (CAN 
2017/233 and CAN 2018/316), Stockholms Sjukhems Jubileumsfond and ASIH Stockholm Södra and ASIH Stockholm Norr. The funding bodies did not have any role in the design of the study and collection, analysis and interpretation of data and in writing of the manuscript.

\section{Availability of data and materials}

The raw-data is available from the corresponding author upon request.

\section{Ethics approval and consent to participate}

The review of the medical records was approved by the Regional Ethical Committee in Stockholm, Dnr 2018/1798-31. Both studies were also approved by the Unit Directors at Unit A and Unit B. All data extracted from the medical records was anonymized before analysis sono individual patients could be identified in the data-set or the analysis. Since the data was anonymized no consent from the patients were needed.

\section{Consent for publication}

Not applicable.

\section{Competing interests}

The authors declare that they have no competing interests.

\section{Author details}

${ }^{1}$ ASIH Stockholm Norr, Medical Home Care and Hospice Ward, Svärdvägen 11 D, SE-182 33 Danderyd, Sweden. ${ }^{2}$ ASIH Stockholm Södra, Medical Home Care and Hospice Ward, Bergtallsvägen 12, SE-125 59 Älvsjö, Sweden. ${ }^{3}$ Karolinska Institutet, Department of Neurobiology, Care Sciences and Society (NVS), Division of Clinical Geriatrics, Blickagången 16, Neo floor 7, SE-141 83 Huddinge, Sweden. ${ }^{4}$ Karolinska Institutet and ASIH Stockholm Södra, Bergtallsvägen 12, SE-125 59 Älvsjö, Sweden.

Received: 30 May 2019 Accepted: 24 September 2019

Published online: 17 October 2019

\section{References}

1. Cocks H, Ah-See K, Capel M, Taylor P. Palliative and supportive care in head and neck cancer: United Kingdom National Multidisciplinary Guidelines. J Laryngol Otol. 2016;130:S198-207.

2. Hasselqvist-Ax I, Riva G, Herlitz J, Rosenqvist M, Hollenberg J, Nordberg P, et al. Early cardiopulmonary resuscitation in out-of-hospital cardiac arrest. N Engl J Med. 2015;372:2307-15.

3. Fowler R, Chang MP, Idris AH. Evolution and revolution in cardiopulmonary resuscitation. Curr Opin Crit Care. 2017;23:183-7.

4. Sehatzadeh S. Cardiopulmonary resuscitation in patients with termina illness: an evidence-based analysis. Ont Health Technol Assess Ser. 2014; 14:1-38.

5. Belanger E, Rodriguez C, Groleau D, Legare F, Macdonald ME, Marchand R. Initiating decision-making conversations in palliative care: an ethnographic discourse analysis. BMC Palliat Care. 2014;13:63.

6. Hirlekar G, Jonsson M, Karlsson T, Hollenberg J, Albertsson P, Herlitz J. Comorbidity and survival in out-of-hospital cardiac arrest. Resuscitation. 2018;133:118-23.

7. Nassar BS, Kerber R. Improving CPR performance. Chest. 2017;152:1061-9.

8. Zhan L, Yang LJ, Huang Y, He Q, Liu GJ. Continuous chest compression versus interrupted chest compression for cardiopulmonary resuscitation of non-asphyxial out-of-hospital cardiac arrest. Cochrane Database Syst Rev. 2017;3:CD010134.

9. Kjorstad OJ, Haugen DF. Cardiopulmonary resuscitation in palliative care cancer patients. Tidsskr Nor Laegeforen. 2013:133:417-21.

10. Duplan KL, Pirret AM. Documentation of cardiopulmonary resuscitation decisions in a New Zealand hospital: a prospective observational study. Intensive Crit Care Nurs. 2016;37:75-81.

11. Bradley NM, Sinclair E, Danjoux C, Barnes EA, Tsao MN, Farhadian M, et al. The do-not-resuscitate order: incidence of documentation in the medical records of cancer patients referred for palliative radiotherapy. Curr Oncol. 2006:13:47-54

12. Malyon AC, Forman JR, Fuld JP, Fritz Z. Discussion and documentation of future care: a before-and-after study examining the impact of an alternative approach to recording treatment decisions on advance care planning in an acute hospital. BMJ Support Palliat Care. 2017. https://doi.org/10.1136/ bmjspcare-2016-001101.
13. Pautex S, Gamondi C, Philippin Y, Gremaud G, Herrmann F, Camartin C, et al. Advance directives and end-of-life decisions in Switzerland: role of patients, relatives and health professionals. BMJ Support Palliat Care. 2018;8: 475-84.

14. Wee S, Chang ZY, Lau YH, Wong Y, Ong C. Cardiopulmonary resuscitationfrom the patient's perspective. Anaesth Intensive Care. 2017:45:344-50.

15. Downey L, Au DH, Curtis JR, Engelberg RA. Life-sustaining treatment preferences: matches and mismatches between patients' preferences and clinicians' perceptions. J Pain Symptom Manag. 2013:46:9-19.

16. Chiang JK, Chen JS, Kao YH. Comparison of medical outcomes and health care costs at the end of life between dialysis patients with and without cancer: a national population-based study. BMC Nephrol. 2019;20:265.

17. Claessens MT, Lynn J, Zhong Z, Desbiens NA, Phillips RS, Wu AW, et al. Dying with lung cancer or chronic obstructive pulmonary disease: insights from SUPPORT. Study to understand prognoses and preferences for outcomes and risks of treatments. J Am Geriatr Soc. 2000;48:S146-53.

18. Murphy E, Froggatt K, Connolly S, O'Shea E, Sampson EL, Casey D, et al. Palliative care interventions in advanced dementia. Cochrane Database Syst Rev. 2016;12:CD011513.

19. Sobanski PZ, Alt-Epping B, Currow DC, Goodlin SJ, Grodzicki T, Hogg K, et al Palliative care for people living with heart failure - European Association for Palliative Care Task Force expert position statement. Cardiovasc Res. 2019. https://doi.org/10.1093/cvr/cvz200.

20. Bern-Klug M. Considering the CPR decision through the Lens of Prospect theory in the context of advanced chronic illness. Gerontologist. 2017;57:61-7.

21. Epstein AS, Shuk E, O'Reilly EM, Gary KA, Volandes AE. We have to discuss it': cancer patients' advance care planning impressions following educational information about cardiopulmonary resuscitation. Psychooncology. 2015;24: 1767-73.

22. Norals TE, Smith TJ. Advance care planning discussions: why they should happen, why they Don't, and how we can facilitate the process. Oncology (Williston Park). 2015;29:567-71.

23. Taubert M, Norris J, Edwards S, Snow V, Finlay IG. Talk CPR - a technology project to improve communication in do not attempt cardiopulmonary resuscitation decisions in palliative illness. BMC Palliat Care. 2018;17:118.

24. Merja S, Lilien RH, Ryder HF. Clinical prediction rule for patient outcome after in-hospital CPR: a new model, using characteristics present at hospital admission, to identify patients unlikely to benefit from CPR after in-hospital cardiac arrest. Palliat Care. 2015;9:19-27.

25. Merino AM, Greiner R, Hartwig K. A randomized controlled trial of a CPR decision Support video for patients admitted to the general medicine service. J Hosp Med. 2017;12:700-4.

26. Fan SY, Wang YW, Lin IM. Allow natural death versus do-not-resuscitate: titles, information contents, outcomes, and the considerations related to do-not-resuscitate decision. BMC Palliat Care. 2018;17:114.

\section{Publisher's Note}

Springer Nature remains neutral with regard to jurisdictional claims in published maps and institutional affiliations.

Ready to submit your research? Choose BMC and benefit from

- fast, convenient online submission

- thorough peer review by experienced researchers in your field

- rapid publication on acceptance

- support for research data, including large and complex data types

- gold Open Access which fosters wider collaboration and increased citations

- maximum visibility for your research: over $100 \mathrm{M}$ website views per year

At $\mathrm{BMC}$, research is always in progress.

Learn more biomedcentral.com/submission 